\title{
The Results of Simulation Training in Pediatric Nursing Students' Education
}

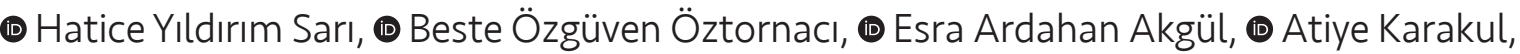 \\ (D) Zehra Doğan, (D) Pınar Doğan \\ İzmir Katip Çelebi University Faculty of Health Sciences, Department of Pediatric Nursing, İzmir, Turkey
}

\begin{abstract}
Aim: Simulation training that started with low realistic models in health education has developed in recent years and is now widely used in medicine and nursing education. The purpose of the present research is to compare nursing students' knowledge, skills, stress and anxiety during pediatric practices and to determine the students' satisfaction and confidence levels related to the use of simulation.

Materials and Methods: This randomized controlled study was conducted with 57 "third-year" students. The students were assigned to experimental $(n=23)$ and control $(n=34)$ groups. To collect the study data, a Student Information Form, Student's Satisfaction and Self-Confidence in Learning scale, Simulation Design scale, Educational Practices Questionnaire, Clinical Stress Questionnaire, State-Trait Anxiety Inventory, Nursing Care Knowledge Assessment Form for Children Suffering a Respiratory disease and Nursing Care Skill Assessment Form for Children Suffering a Respiratory disease were used. While the students in the experimental group had simulation training about Nursing Care of Child Suffering a Respiratory disease, the students in the control group were trained with traditional education methods. The students in both groups were observed while they gave care in the hospital environment.

Results: Clinical stress, state-trait anxiety and clinical skill scores of the students in the experimental group were higher than the control group. Simulation training contributed to the development of their self-confidence positively.

Conclusion: In this study, the simulation training was beneficial, and students' clinical application skill achievements improved.

Keywords: Pediatrics, nursing education, simulation
\end{abstract}

\section{Introduction}

Simulation training is an effective method of training which enables nursing students to gain skills in a controlled environment. Students who gain basic skills in a controlled environment perform healthcare interventions needed for the sick child and his/her family in the clinical setting more safely. Students are more successful in establishing a connection between theory and practice thanks to simulation training. Students are expected to perform interventions correctly without harming the child. Students are also expected to become prepared for clinical practice and to be more successful in performing interventions in pediatric patients through simulation training in an environment quite similar to actual practice environments in which patient reactions are revealed $(1,2)$.

Respiratory-tract diseases are the most common diseases and the leading cause of deaths especially in children under the age of five worldwide $(3,4)$. These diseases are also the leading cause of presentations to pediatric outpatient clinics, admissions to pediatric clinics, and antibiotic use especially in winter months, (5). According to the World Health Organization 2015 data, 16\% of deaths in children under 5 years old occurred due to pneumonia. This rate 
is higher than the rates of deaths caused by diseases like human immunodeficiency virus, malaria or measles $(6,7)$. A retrospective study conducted to investigate the causes of deaths in children aged 3 to 8 years in a hospital in the past 26 years reported that the rate of bronchopneumonia in diseases leading to deaths in children was $47 \%$ (8).

Since the provision of appropriate care and intervention in respiratory diseases that cause morbidity and mortality in millions of children all over the world is of importance, simulation training given in order to contribute to the development of psychomotor skills of working nurses and to support students with limited clinical experience in order to improve their clinical skills through nursing care scenarios regarding a child having a respiratory disease will make it possible to give appropriate care to a child with a respiratory disease (9-13). Therefore, this study was aimed at investigating the effect of simulation training on the knowledge, skills, stress and anxiety of third-year students taking a pediatric nursing course in clinical practice and to determine these students' satisfaction and self-confidence levels related to the use of simulation.

\section{Materials and Methods}

Type of Study: The study was conducted as a randomized control experimental study.

Hypotheses:

1. Clinical stress levels of students who receive simulation training are lower than those of students trained by traditional methods.

2. Anxiety levels of students who receive simulation training are lower than those of students trained by traditional methods.

3. The scores obtained from the Nursing Care Knowledge Assessment Form for Children Suffering a Respiratory disease by students who receive simulation training are higher than the scores obtained by those trained by traditional methods.

4. The scores obtained from the Nursing Care Skills Assessment Form for Children Suffering a Respiratory disease by students who receive simulation training are higher than the scores obtained by those trained by traditional methods.

5. Satisfaction and self-confidence levels of students who receive simulation training are higher than those of students trained by traditional methods.

\section{Study Sample}

The study was conducted with 57 third-year students taking the Pediatric Nursing course in the spring semester of 2016-2017 academic year. The Pediatric Nursing course includes 5 hours of theory and 8 hours of practice per week. All the students receiving the theoretical training were numbered on a list. Of them, 57 selected by a lottery method were randomly assigned to the experimental $(n=23)$ and control $(n=34)$ groups. While the students in the experimental group had simulation training, the students in the control group were trained with a traditional method. Students who have graduated from any of the health departments in high school education and/or are currently working in the field of health were excluded from the research.

\section{Sample Size Calculation}

In the Gpower statistical program, it was determined that 27 students should be sampled for each group according to the comparison of mean clinical stress score at a power of 0.80 and an acceptable Type I error size of 0.05 in groups.

\section{Scenario}

A 5-month-old infant with bronchopneumonia with nasal obstruction, coughing and wheezing complaints.

Students gain skills;

- Being able to evaluate the baby's physical examination results correctly,

- Being able to monitor the baby,

- Being able to apply nasal lavage to baby,

- Being able to give medication by nebulization,

- Being able to give oxygen to the baby,

- Being able to make attempts to calm the mother and the baby.

\section{Data Collection Tools}

Student Information Form: The Form includes 4 items questioning the students' age, gender, school achievement and rating of the simulation training.

Student Satisfaction and Self-Confidence in Learning scale: The 13-item original scale developed by Jeffries and Rizzolo (14) (2006) was adapted into Turkish by Unver et al. (15) (2017). The Turkish version of the scale has 12 items. The 5-point Likert-Type scale consists of 2 subscales: Satisfaction with Current Learning and Self-Confidence in Learning. The Cronbach's alpha value was 0.85 for the "Satisfaction with Current Learning" subscale, 0.77 for the "Self Confidence in Learning" subscale and 0.89 for the overall scale. The higher the total score obtained from the scale is, the higher the Student's Satisfaction and Self-Confidence is. In order to use the scale in the present study, permission was obtained from Unver et al. (15).

Simulation Design scale: This scale was developed by Jeffries and Rizzolo (14) (2006). The reliability and validity study of the Turkish version of the scale was conducted by Unver et al. (15) (2017). The Simulation Design scale has the following 5 subscales including 20 items: Objectives and Information, Support, Problem Solving, Feedback/Guided Reflection and Fidelity (Realism). The Cronbach's alpha values for the subscales were $0.77,0.73,0.76,0.75$ and 0.86 respectively. The Cronbach's alpha value for the overall scale was 0.90. The items in the scale are rated in two sections. In the first section, whether the best simulation design elements are implemented in simulation is rated. In 
the second section, how important the simulation design elements are to the students is rated. High scores indicate that students' awareness of simulation design elements has increased. In order to use the scale in the present study, permission was obtained from Unver et al. (15).

Educational Practices Questionnaire: The scale was developed by Jeffries and Rizzolo (14) (2006). The reliability and validity study of the Turkish version of the scale was conducted by Unver et al. (15) (2017). The Educational Practices Questionnaire has the following 4 subscales including 16 items: Active Learning, Collaboration, Diverse Ways of Learning and High Expectations. The Cronbach's alpha values for the subscales and for the overall scale were $0.86,0.61,0.86,0.85$ and 0.91 respectively. The items in the scale are rated in two sections. In the first section, whether the best educational practice elements are implemented in simulation training is rated. In the second section, how important the educational practice elements are to the students is rated. In order to use the scale in the present study, permission was obtained from Unver et al. (15).

Clinical Stress Questionnaire: The scale developed by Pagana in 1989 to identify and assess the appraisal of stress in the first clinical experience of nursing students as threatening or challenging is a self-report Likert-Type instrument. The reliability and validity study of the Turkish version of the questionnaire was conducted by Sendir and Acaroglu (16) (2008). The questionnaire has 4 subscales: threat, fight, damage and benefit emotions. Each item is rated on a 5-point scale. While a low score indicates that the stress level is low, a high score indicates that the stress level is high. In order to use the questionnaire in the present study, permission was obtained from Sendir and Acaroglu (16).

State-Trait Anxiety Inventory (Self-Report Form) (STAI Form Tx 1/2): The State-Trait Anxiety Inventory developed by Spielberger et al. (17), and adapted to Turkish by Öner and Le Compte (18) (1985) includes 40 items. Of the items, 20 assess state anxiety and the other 20 assess trait anxiety. This inventory is administered to individuals over 14 years of age. In general, high levels of state and trait anxiety scores indicate a high level of anxiety, and individuals with scores above 60 need professional help.

Nursing Care Knowledge Assessment Form for Children Suffering a Respiratory disease: This form prepared in line with the literature and expert opinion was aimed at determining to what extent the students knew the health care to be given to a 5-month-old infant who was diagnosed with bronchopneumonia and had respiratory complaints such as nasal obstruction, coughing and wheezing. The form included 12 statements measuring the students' knowledge on the "Evaluation of Respiratory System in Children", "Oxygen Administration", "Medication Administration with Nebulizer" and "Intranasal Medication Administration". The students were asked to choose one of the 3 choices for each statement: "True", "False" or "I do not know".

Nursing Care Skill Assessment Form for Children Suffering a Respiratory disease: This form was aimed at determining how well the students implemented their skills of health care to be given to a 5-month-old infant who was diagnosed with bronchopneumonia and had respiratory complaints such as nasal obstruction, coughing and wheezing. Whether or not the students fulfilled the implementation steps included in the nursing skills regulations regarding "Evaluation of Respiratory System in Children", "Oxygen Administration", "Medication Administration with Nebulizer" and "Intranasal Medication Administration" was observed and assessed. The implementation steps were assessed by the researcher as "Fulfilled" or "Not Fulfilled". Expert opinion was obtained for the validity and reliability of the form.

\section{Procedure}

Before the study was conducted, approvals were obtained from the Non-Interventional Clinical Research Ethics Committee of İzmir Katip Çelebi University (approval number: 156/2017). Students were informed about the study and written consent was obtained from the volunteer students and then randomization was carried out.

Step 1: After the students were randomly assigned to the experimental and control groups, the Nursing Care Knowledge Assessment Form for Children Suffering a Respiratory disease was administered to all the students in the pre-simulation training period. It was a single-blind experiment. All the students were asked to use pseudonyms on the answer sheets for the pre-test and post-test.

Step 2: The students in the experimental group had the nursing care simulation training for children with a respiratory disease in two separate stations. During the simulation training, the students were observed in line with the Nursing Care Knowledge Assessment Form for Children Suffering a Respiratory disease. After the debriefing, the students were administered the Student Satisfaction and Self-Confidence scale in Learning, Simulation Design scale and Educational Practices Questionnaire.

Step 3: All the students were administered the Nursing Care Knowledge Assessment Form for Children Suffering a Respiratory disease after the training.

Step 4: All the students in both groups were administered the Trait Anxiety Inventory and PAGANA Clinical Stress Questionnaire.

Step 5: All the students in both groups were observed in line with the Nursing Care Skill Assessment Form for Children Suffering a Respiratory disease while they provided healthcare for a child with a respiratory disease during their 15-day clinical practices. Before the provision of healthcare was started, the students were administered the State Anxiety Inventory. 
The simulation training was carried out in the fully equipped Nursing Skill Laboratory in two stations on two moderately realistic baby mannequins. The implementation of the scenario took about 15-20 minutes. In the scenario, the researchers involved in the study acted as nurses and mothers in both stations. Two researchers observed and evaluated the students. While the students gave care to an actual patient in a clinical setting, at least one researcher observed and evaluated them. To ensure compliance between observers, the researchers were trained on nursing care of the infant.

\section{Statistical Analysis}

In the research, descriptive statistics such as numbers, percentages and mean values were used. While the pre-and post-simulation training knowledge and skill scores of the experimental group were compared with the dependent Samples t-test (Wilcoxon). Knowledge, stress and anxiety scores of the experimental group were compared with those of the control group using the independent t-test (Mann Whitney $U$ test). The experimental group's postsimulation training scores for the Student Satisfaction and Self-Confidence in Learning scale, Simulation Design scale and Educational Practices Questionnaire were assessed with the descriptive statistics. The statistical significance was accepted as $\mathrm{p}<0.05$.

\section{Results}

The mean age of the students who participated in the study was $21.24 \pm 1.43$ years. Of the students, $80.7 \%(n=46)$ were female. The students' mean cumulative grade point average (CGPA) was $2.69 \pm 32$. The comparison of the experimental and control groups in terms of gender $(p=0.080)$ and CGPA $(p=0.185)$ revealed that there was no difference between the groups.

There were statistically significant differences between the experimental and control groups in terms of their clinical stress $(p=0.006)$, trait anxiety $(p=0.038)$, state anxiety $(p=0.033)$, and clinical skill $(p=0.009)$ scores. The experimental group's clinical stress, trait anxiety, state anxiety and clinical skill scores were higher than were those of the control group. The comparison of knowledge scores of the groups revealed that there was a difference in favor of the students in the experimental group; however, the difference was not statistically significant $(p=0.715)$ (Table I).

The mean clinical skill score of the students in the experimental group, which was $14.43 \pm 7.56$ before the training, increased to $17.95 \pm 6.48$, but the increase was not statistically significant $(p=0.054)$. The case was the same for the mean knowledge level scores. It was $7.69 \pm 0.86$ before the simulation training, and increased to $8.00 \pm 1.59$ after the simulation training, but this increase was not statistically significant either $(p=0.389)$ (Table II).
The mean total scores obtained by the students who participated in the simulation training were $3.76 \pm 0.78$ for the Student Satisfaction and Self-Confidence scale in Learning, $3.97 \pm 0.87$ for the Simulation Design scale scores, $4.27 \pm 0.77$ for the Importance of Simulation Design, 3.74 \pm 0.69 for the Educational Practices Questionnaire, and $4.14 \pm 0.75$ for the Importance of Educational Practices. When the students were asked to evaluate the simulation training they had out of 10 points, the mean of the points they gave was $7.21 \pm 1.56$ (minimum 3 and maximum 10) (Table III).

\section{Discussion}

In this present study aimed at investigating the teaching of nursing care skills through simulation use and the effects of the training on care of respiratory diseases, one of the most common health problems in children. Stress and state anxiety levels of the students participating in the simulation training were higher when they started clinical practices. These students' high levels of stress and anxiety may have been due to their high levels of trait anxiety when they started clinical practices. That the stress scores of the students in the experimental group were also high might be related to the fact that the students participating in the simulation training felt that they were expected to achieve better. In the study of Gore et al. (19) (2011), the anxiety levels of nursing students who received simulation training were reported to be significantly lower in their first clinical experience. In their study on the nursing approach to a young child with asthma, Cantrell et al. (9) (2008) found that some of the students experienced stress and performance anxiety during their participation in the clinical simulation training. The simulation training affects the students' anxiety levels either positively or negatively: in some studies, it decreases (19) and in some studies, it increases (9). Keeping in mind the fact that students' anxiety levels during the simulation training can vary will positively contribute to the support provided for them.

The most important result expected from the research was that the student would better perform the clinical skills taught in the simulation training in an actual clinical setting where he/she encountered a real patient. As shown in Table I, the students who participated in the simulation training were more successful in providing the nursing care to a baby with respiratory difficulty. According to the evaluation made during the simulation training, the students in the experimental group were more successful in the actual clinical setting and their clinical skill scores were higher. In LeFlore et al.'s (11) study (2012), knowledge acquisition and healthcare levels of the nursing students who had simulation training on pediatric respiratory diseases (asthma, bronchiolitis, pneumonia and cystic fibrosis) increased significantly. In Kang et al.'s (13) study (2015), a significant increase was observed in nursing 
care knowledge of students after simulation training on a child with bronchiolitis was given. Respiratory distress is a condition that makes children feel uncomfortable. Therefore, creating a setting where the scenario brings the patient's reactions to the forefront during the simulation training will increase the students' success levels when they meet an actual patient.

In the present study, there was no difference between the post-simulation knowledge scores of the nursing students in the experimental and control groups. That is probably because they took the same theoretical course. Similarly, there was no difference between the pre-and post-simulation training knowledge scores of the students in the experimental group. In Pauly-O'Neill and Prion's (20) (2013) simulation study on students' skills of drug preparation for pediatric patients, the students' post-intervention knowledge scores were reported as high. In a simulation study conducted by Parker et al. (21) (2011) with undergraduate nursing students who took a Child Health Course, the students' post-simulation training scores were not different from their pre-simulation training scores, similar to this study. Knowledge scores' being influenced by knowledge acquired through the theoretical education was regarded as something expected.
The mean scores the students who participated in the present research obtained from the Student Satisfaction and Self-Confidence scale, Simulation Design scale and Educational Practices Questionnaire, which ranged between 3.76 and 3.97, were above the average. The Importance score given by the students to rate the Simulation Design scale and Educational Practices Questionnaire were over 4 out of 5. It was determined that the students were generally satisfied with their simulation experiences, that they perceived the characteristics of the simulation favorably, and that they thought that simulation training contributed to their development of self-confidence positively. In the literature, the scores obtained in several studies in which the same scales were used were similar ( 3.45 to 4.40 ) to those obtained by Cantrell et al. (9) (2008). In many studies, the mean scores obtained from the scales were generally above 4 (2225). Those studies also emphasized that simulation training increased students' confidence and satisfaction levels (2527).

When the students were asked to evaluate the simulation training they had out of 10 points, the mean of the points they gave was $7.21 \pm 1.56$ (Table III). In Doğan's (28) (2015) study conducted with nursing students having simulation training,

Table I. Differences between the experimental and control groups in terms of clinical stress, anxiety, clinical skill and knowledge levels

Post-simulation training clinical practice

\begin{tabular}{|l|l|l|l|l|}
\hline & Experimental group & Control group & Analysis Mann-Whitney U & p value \\
\hline PAGANA clinical stress score & $29.04 \pm 9.83$ & $21.88 \pm 7.88$ & 223.500 & 0.006 \\
\hline Trait anxiety score & $46.56 \pm 5.55$ & $43.58 \pm 3.18$ & 255.500 & 0.038 \\
\hline State anxiety score & $46.56 \pm 5.55$ & $43.51 \pm 3.16$ & 260.000 & 0.033 \\
\hline Clinical skill Score & $17.95 \pm 6.48$ & $13.85 \pm 5.82$ & 231.000 & 0.009 \\
\hline Knowledge score & $8.00 \pm 1.59$ & $7.68 \pm 1.45$ & 369.000 & 0.715 \\
\hline
\end{tabular}

Table II. Comparison of the pre-during and post-simulation training knowledge and clinical skill scores of the experimental group

\begin{tabular}{|l|l|l|l|l|}
\hline & $\begin{array}{l}\text { Experimental group pre-during the } \\
\text { simulation training }\end{array}$ & $\begin{array}{l}\text { Experimental group post } \\
\text { simulation training (in the clinic) }\end{array}$ & $\begin{array}{l}\text { Analysis } \\
\text { Wilcoxon }\end{array}$ & $\mathbf{p}$ value \\
\hline Clinical skill scores-(during) & $14.43 \pm 7.56$ & $17.95 \pm 6.48$ & -1.931 & 0.054 \\
\hline Knowledge scores-(pre) & $7.69 \pm 1.86$ & $8.00 \pm 1.59$ & -0.861 & 0.389 \\
\hline
\end{tabular}

Table III. Evaluations of the students in the experimental group regarding the simulation training

\begin{tabular}{|l|l|l|l|}
\hline & $X \pm$ SD & Min. & Max. \\
\hline Student Satisfaction and Self-Confidence scale in Learning score & $3.76 \pm 0.78$ & 2.08 & 4.83 \\
\hline Simulation Design scale & $3.97 \pm 0.87$ & 1.55 & 6.00 \\
\hline Simulation Design scale (Importance score) & $4.27 \pm 0.77$ & 1.55 & 5.00 \\
\hline Educational Practices Questionnaire score & $3.74 \pm 0.69$ & 1.75 & 4.63 \\
\hline Educational Practices Questionnaire (Importance score) & $4.14 \pm 0.75$ & 1.50 & 5.00 \\
\hline Simulation Training Evaluation score & $7.21 \pm 1.56$ & 3 & 10 \\
\hline
\end{tabular}

SD: Standard deviation, Min: Minimum, Max: Maximum 
the students rated the contribution of the simulation training at 8.4 points out of 10 when a highly realistic human simulator was used, and 7.9 points when the simulation training was performed with a standard human patient simulator. In another study by Doğan et al. (29) (2016) conducted in 2016, the students who had their training on a moderately realistic pediatric mannequin rated the simulation training at 6.2 points out of 10 . When the students assessed the effect of the simulation training on the clinical setting, they gave higher scores in the studies in which highly realistic human simulators were used in the training. Students' expectation from simulation training is that simulators should be highly realistic.

\section{Conclusions}

In this present study, because the randomization was realized by means of a lottery method, it was not possible to prevent trait anxiety levels between the groups from being different. Therefore, although it was thought that the high level of state anxiety in the experimental group was due to the increase in the students' awareness, it was not thoroughly evaluated. Thus, it is suggested that trait anxiety scores should also be included in the randomization criteria of future studies.

In conclusion, in this present study, the students' success in the application of clinical skills increased in the group which received the simulation training. Based on this, it is recommended that to tackle the problems encountered especially in critical patient care and child health, simulation training should be widely used.

\section{Key Points}

- Simulation training is an effective method of training which enables nursing students to gain skills in a controlled environment.

- Simulation-based training reduces students' risk of misapplication due to lack of experience in becoming prepared for clinical practices.

- Students are more successful in performing interventions in pediatric patients through simulation training in an environment quite similar to actual practice environments.

\section{Ethics}

Ethics Committee Approval: This study was approved by the Non-Interventional Clinical Research Ethics Committee of İzmir Katip Çelebi University (approval number: 156/2017).

Informed Consent: Written consent was filled out and given by the students.

Peer-review: Externally and internally peer-reviewed.

\section{Authorship Contributions}

Concept: H.Y.S., E.A.A., B.Ö.Ö., A.K., Z.D., P.D., Design: H.Y.S., Data Collection or Processing: E.A.A., B.Ö.Ö., A.K.,
Z.D., P.D., H.Y.S., Analysis or Interpretation: H.Y.S., E.A.A., A.K., Literature Search: H.Y.S., E.A.A., B.Ö.Ö., A.K., Z.D., P.D., Writing: H.Y.S., E.A.A., B.Ö.Ö., A.K.

Conflict of Interest: No conflict of interest was declared by the authors.

Financial Disclosure: The authors declared that this study received no financial support.

\section{References}

1. Cant RP, Cooper SJ. Simulation-based learning in nurse education: systematic review. I Adv Nurs 2010;66:3-15.

2. Kapucu S, Bulut H. Turkish nursing students' views of their clinical learning environment: a focus group study. Pak J Med Sci 2011;27:1149-53.

3. Jroundi I, Mahraoui C, Benmessaoud R, et al. Risk factors for a poor outcome among children admitted with clinically severe pneumonia to a university hospital in Rabat, Morocco. Int I Infect Dis 2014;28:164-70.

4. Tanır G, Aytekin C. Çocuklarda alt solunum yolu enfeksiyonları. Sürekli Tıp Eğitimi Dergisi 2001;10:382-5.

5. Le Roux DM, Myer L, Nicol MP, Zar H). Incidence and severity of childhood pneumonia in the first year of life in a South African birth cohort: the Drakenstein child health study. Lancet Glob Health 2015;3:95-103.

6. World Health Organization WHO Causes of child mortality. 2015; http://www.who.int/gho/child_health/mortality/causes/ en/ Accessed 20 July 2017.

7. Wang $H$, Liddell $C A$, Coates $M M$, et al. Global, regional, and national levels of neonatal, infant, and under-5 mortality during 1990-2013: A systematic analysis for the Global Burden of Disease Study 2013. Lancet 2014;384:957-79.

8. Craver R, Springer I, Begue R. Infections in a children's hospital autopsy population. Fetal Pediatr Pathol 2014;33:135-44.

9. Cantrell MA, Meakim C, Cash K. Development and evaluation of three pediatric-based clinical simulation. Clin Simul Nurs 2008;4:21-8.

10. Sigalet E, Donnon T, Grant V. Undergraduate students' perceptions of and attitudes toward a simulation-based Interprofessional curriculum. The KidSIM Attitudes Questionnaire. Simul Healthc 2012;7:353-8.

11. LeFlore IL, Anderson M, Zielke MA, et al. Can a virtual patient trainer teach student nurses how to save lives-teaching nursing students about pediatric respiratory diseases. Simul Healthc 2012;7:10-7.

12. Dowson A, Russ S, Sevdalis N, Cooper M, De Munter C. How in situ simulation affects paeditric nurses' clinical confidence. $\mathrm{Br}$ ) Nurs 2013;22:610-7.

13. Kang KA, Kim S, Kim SJ, Oh J, Lee M. Comparison of knowledge, confidence in skill performance (CSP) and satisfaction in problem-based learning (PBL) and simulation with PBL educational modalities in caring for children with bronchiolitis. Nurse Educ Today 2015;35:315-21.

14. Jeffries PR, Rizzolo MA. Designing and implementing models for the innovative use of simulation to teach nursing care of ill adults and children: a national, multi-site, multi-method study. National League for Nursing and Laerdal Medical, New York, 2006.

15. Unver $\mathrm{V}$, Basak $T$, Watts $\mathrm{P}$, et al. The reliability and validity of three questionnaires: the student satisfaction and self- confidence 
in learning scale, simulation design scale, and educational practices questionnaire. Contemp Nurse 2017;53:60-74.

16. Sendir M, Acaroglu R. Reliability and validity of Turkish version of clinical stress questionnaire. Nurse Educ Today 2008;28:73743.

17. Spielberger $C D$, Gorsuch RL, Lushene R, Vagg PR, Jacobs $G A$. Manual for the State-Trait Anxiety Inventory. Palo Alto, CA, Consulting Psychologists Press, 1983.

18. Öner N, Le Compte A. State-Trait Anxiety Inventory Manual. İstanbul, Turkey, Boğaziçi University Press, 1985.

19. Gore T, Hunt CW, Parker F, Raines KH. The effects of simulated clinical experiences on anxiety: Nursing students' perspectives. Clin Simul Nurs 2011;7:175-80.

20. Pauly-O'Neill S, Prion S. Using integrated simulation in a nursing program to improve medication administration skills in the pediatric population. Nurs Educ Perspect 2013;34:148-53.

21. Parker RA, McNeill JA, Pelayo LW, Goei KA, Howard J, Gunter MD. Pediatric clinical simulation: A pilot project. I Nurs Educ 2011;50:105-11.

22. Mills I, West $C$, Langtree $T$, et al. Putting it together: Unfolding case studies and high-fidelity simulation in the first-year of an undergraduate nursing curriculum. Nurse Educ Pract 2014; 14:12-7.
23. Wang AL, Fitzpatrick IJ, Petrini MA. Comparison of two simulation methods on Chinese BSN students' learning. Clin Simul Nurs 2013;9:207-12.

24. Liaw SY, Scherpbier A, Klainin-Yobas P, Rethans IJ. Rescuing a patient in deteriorating situations (RAPIDS): an evaluation tool for assessing simulation performance on clinical deterioration. Resuscitation 2011;82:1434-9.

25. Swenty CF, Eggleston BM. The evaluation of simulation in a baccalaureate nursing program. Clin Simul Nurs 2011;7:181-7.

26. Golinveaux J, Gerbert B, Cheng I, et al. Oral health education for pediatric nurse practitioner students. I Dent Educ 2013;77:58190.

27. Lewis DY, Ciak AD. The impact of a simulation lab experience for nursing students. Nurs Educ Perspect 2011;32:256-8.

28. Doğan, P. Hemşirelik eğitiminde farklı simülasyon yöntemlerinin öğrencilerin eleştirel düşünme eğilimlerine ve öz-etkililik düzeylerine etkisi. Unpublished PhD Thesis, İstanbul University, 2015.

29. Doğan Z, Akarsu Ö, Yıldız S, Aydoğan MN, Bircan M. Use of Simulation in Pediatric Nursing Education: nursing students experiences. Eur I Pediatr 2016;175:1393-880. https://www.ncbi.nlm.nih.gov/ pubmed/?term=Eur+J+Pediatr+2016\%3B175\%3A1393-880 